\title{
Alma, Mente e Cérebro na Pré-história e nas Primeiras Civilizações Humanas
}

\author{
Soul, Mind and Brain in Pre-history and Early Human Civilizations
}

\author{
Fabiano dos Santos Castro ${ }^{a} \&$ J. Landeira-Fernandez ${ }^{*}, a, b$ \\ a Pontifícia Universidade Católica do Rio de Janeiro \\ ${ }^{b}$ Universidade Estácio de Sá
}

\begin{abstract}
Resumo
Atualmente, o debate sobre a natureza da mente humana vem tomando novos rumos graças ao desenvolvimento de diversos estudos, no campo das neurociências, que investigam a localização das funções cerebrais. Esses trabalhos vêm contribuindo para uma melhor compreensão dos substratos neurais das funções mentais, bem como da etiologia de diversos transtornos mentais. Entretanto, o conhecimento acumulado pela neurociência não ocorreu de forma súbita. $\mathrm{Na}$ verdade, o estudo das relações entre o cérebro e a mente não é recente. Da pré-história aos dias atuais, surgiram vários tipos de questionamentos a respeito da possível materialidade e localização das funções mentais humana. O presente trabalho apresenta, de forma histórica, como populações pré-históricas, assim como as primeiras civilizações, localizadas no Egito, na Mesopotâmia, na Índia e na China, desenvolveram e utilizaram conceitos relacionados com a alma, a mente e o cérebro humano.
\end{abstract}

Palavras-chaves: Relação mente-corpo; Civilizações antigas; História da Neurociência.

\begin{abstract}
Currently, the debate about the nature of the human mind is taking new directions through the development of several studies in the field of neuroscience which investigates the location of brain functions. These studies have contributed to a better understanding of the neural substrates of mental functions and the etiology of various mental disorders. However, the knowledge developed by neuroscience did not occur abruptly. Indeed, the study of mind-brain relationship is not new. From pre-history to the present days, various different types of inquiries have been made about the possible materiality and location of human mental functions. This paper presents, in a historic manner, how prehistoric populations as well as early civilizations located in Egypt, Mesopotamia, India, and China developed and employed concepts related to the soul, the mind and the human brain.

Keywords: Mind-body relationships; Ancient civilizations; History of Neuroscience.
\end{abstract}

Dos mitos da criação presentes nas culturas antigas às teorias da física moderna, questões relacionadas com a existência humana e o mundo que a cerca sempre geraram indagações. Entre todas essas questões, talvez a mais intrigante seja aquela relacionada com a própria atividade mental. Apesar do avanço de conhecimento em geral, a natureza da mente humana permanece ainda, em grande parte, sem respostas definitivas.

O debate acerca da natureza da mente humana vem tomando novos rumos graças à influência do conhecimento biológico e à crescente investigação sobre a atividade neural (P. M. Churchland, 2004). O crescimento

*Endereço para correspondência: Pontifícia Universidade Católica do Rio de Janeiro, Laboratório de Análise de Dados, Departamento de Psicologia, Rua Marquês de São Vicente, 225, Rio de Janeiro, RJ, Brasil, CEP 22453-900. Tel.: +(55) 213227 1186; Fax: +(55) 213227 1187. Email: landeira@puc-rio.br

Gostaríamos de prestar nossos agradecimentos à contribuição dos dois pareceristas ad hoc pelas sugestões de modificações feitas ao texto original do campo das investigações sobre a localização das funções cerebrais pela neurociência tem contribuído para uma melhor compreensão dos substratos neurais da consciência humana. Entretanto, o conhecimento produzido por essa área de saber não ocorreu subitamente. Da préhistória aos dias atuais, diferentes formas de reflexão a respeito das possíveis relações entre o corpo e suas funções mentais (ou alma) foram produzidas (Kristensen, Almeida, \& Gomes, 2001; Liu \& Apuzzo, 2003).

De fato, diversas civilizações antigas desenvolveram diferentes perspectivas, com graus distintos de complexidade, sobre essa relação entre mente e corpo (Méndez, Botella, \& Vargas II, 2001). Por exemplo, as antigas civilizações do Egito, da Mesopotâmia, da Índia e da China construíram, dentro de seu contexto histórico-cultural, um conhecimento próprio, com o objetivo de compreender como ocorre essa relação entre a mente e o corpo que a contém (Finger, 1994). Registros históricos dessas civilizações representam as primeiras tentativas de localizar a alma, ou seja, identificar em que região cor- 
poral estaria armazenada a essência do ser e a fonte de toda a vida mental. Assim, conhecer as diferentes perspectivas dessas civilizações sobre a relação entre mente e corpo é um recurso valioso, pois nos permite observar, de uma maneira ampla, as primeiras considerações feitas sobre questões ainda presentes atualmente.

Ressalta-se que o presente trabalho não discute a visão sobre essas questões presente na Grécia Antiga. Isso se deve ao alto grau de complexidade dessa civilização e ao rico campo de formulações realizadas por filósofos e médicos clássicos, como Aristóteles, Platão, Alcmeão e Hipócrates (Crivellato \& Ribatti, 2007). Dessa forma, o presente trabalho pretende, inicialmente, apresentar alguns indícios que sugerem uma possível importância atribuída ao cérebro por hominídeos, assim como pelo homem pré-histórico. Em seguida, serão apresentadas as principais idéias a respeito do debate corpo-mente encontradas nas antigas civilizações egípcia, mesopotâmica, indiana e chinesa.

A metodologia empregada no presente trabalho consiste em uma narrativa ampla de diferentes fontes relacionadas aos diversos temas abordados pela literatura, desde aspectos específicos de determinadas áreas até aspectos gerais sobre as próprias civilizações supracitadas. Assim, realiza-se uma descrição histórica das perspectivas dessas antigas civilizações sobre os temas aqui tratados. Cabe ressaltar que esse tipo de abordagem caracterizada por um pouco aprofundamento das fontes de informação marca uma limitação do estudo. A temática discutida, no entanto, é relevante, devido à inegável carência de uma organização formal sobre a relação mente e corpo, já presente nessas civilizações antigas.

\section{Os Hominídeos, o Homem Pré-Histórico e a Trepanação}

É muito provável que o homem pré-histórico ou mesmo espécies hominídeas já extintas tenham notado que traumas cranianos eram capazes de produzir sérios distúrbios mentais, como perda da consciência, danos à memória, convulsões e alterações do comportamento (Finger, 1994). Entretanto, a ausência de registros escritos impede que se possa determinar com exatidão que tipo de conhecimento essas culturas tinham sobre a relação entre o cérebro e as funções mentais. Dessa forma, a análise de crânios descobertos através de escavações arqueológicas constitui um dos principais elementos para tentar responder a essa questão (Andrushko \& Verano, 2008; Broca, 1867; Finger, 1994; Horsley, 1888; Jackes, 2004; Lillie, 1998; Liu \& Apuzzo, 2003; Marino-Junior \& Gonzales-Portillo, 2000; Persuad, 1984; Walker, 2001).

Traumatismos cranianos, capazes de causar lesões no cérebro, podem ser encontrados por toda a evolução de nossa espécie (Walker, 2001). Por exemplo, um crânio da espécie Australopithecus africanus, estimado em três milhões de anos, apresentava diversas fraturas, umas próximas às outras, muito provavelmente associadas a agressões intraespecíficas (Finger, 1994). A descoberta de outros crânios da espécie Homo erectus também demonstrou algumas lesões desse tipo na caixa craniana. Entre esses crânios estão o "Homem de Java" (500-300 mil anos atrás) e o "Homem de Pequim" (300-100 mil anos atrás). Aparentemente, um bom número dessas lesões foi capaz de provocar a morte (Finger, 1994). Evidências dessa natureza foram encontradas também na espécie Homo neanderthalensis (100-40 mil anos atrás). Fósseis dessa espécie encontrados na caverna de Shanidar, no Iraque, apresentavam crânios com lesões anteriores à morte, como uma ferida no topo da cabeça e outra na região do olho (Trinkaus \& Zimmerman, 2005). A análise de diversos crânios de nossa espécie (Homo sapiens) encontrados em sítios da China, da América do Norte e do Quênia, datados do período Neolítico (10.000 a.C.), também indica que a região da cabeça era bastante visada durante confrontos interpessoais (Jackes, 2004). Para Finger (1994), esse tipo de evidência arqueológica sugere que o cérebro, ou pelo menos a região da cabeça, era vista como área crítica para as funções básicas da vida.

A trepanação (do grego trupanon, perfuração, abrir um buraco) é um procedimento cirúrgico que consiste na retirada de uma porção do crânio (Blos, 2003). Essa técnica foi muito utilizada durante as Idades Antiga e Média e largamente utilizada durante os séculos XVIII e XIX com fins terapêuticos (Gross, 1999b; Jensen \& Stone, 1997; Mariani-Costantini, Catalano, di Gennaro, di Tota, \& Angeletti 2000; Wagner, 1890). Crânios trepanados foram encontrados também em culturas humanas pré-históricas datadas do período Neolítico (10.000 a.C.) (Gerszten, Gerszten, \& Allison, 1998; Piek, Lidke, Terberger, von Smekal, \& Gaab, 1999). Essas descobertas constituem a principal evidência de que essas culturas possivelmente atribuíam ao cérebro um papel importante na regulação das funções mentais, uma vez que esses orifícios cranianos foram deliberadamente realizados de forma cirúrgica, para atingir algum determinado propósito (Finger, 1994).

Até meados do século XIX diversos crânios trepanados foram encontrados em sítios arqueológicos espalhados por diversas regiões da Europa, em países como, por exemplo, Alemanha, Áustria, Polônia, Portugal, Inglaterra, Itália, Dinamarca, Suécia, Rússia, Espanha e França. O primeiro crânio trepanado foi encontrado em 1685, por Bernard de Montfauchon (1655-1741), em Cocherel, na França (Clower \& Finger, 2001; Feldman \& Goodrich, 2001; Finger, 1994). Entretanto, os orifícios resultantes da trepanação, até então, eram considerados frutos da ação de armas, lesões acidentais ou alterações feitas após a morte.

Foi apenas em 1865, em uma viagem a Cuzco, no Peru, que o arqueólogo americano Ephraim George Squier (1821-1888) encontrou um crânio que apresentava um 
pequeno orifício retangular de $15 \mathrm{~mm}$ por $17 \mathrm{~mm}$, datado por volta de 1500-1400 a.C. Devido às características do orifício, Squier (1865) concluiu que havia sido deliberadamente feito por mãos humanas (Clower \& Finger, 2001; Finger \& Fernando, 2001). A Figura 1 apresenta uma ilustração desse crânio.

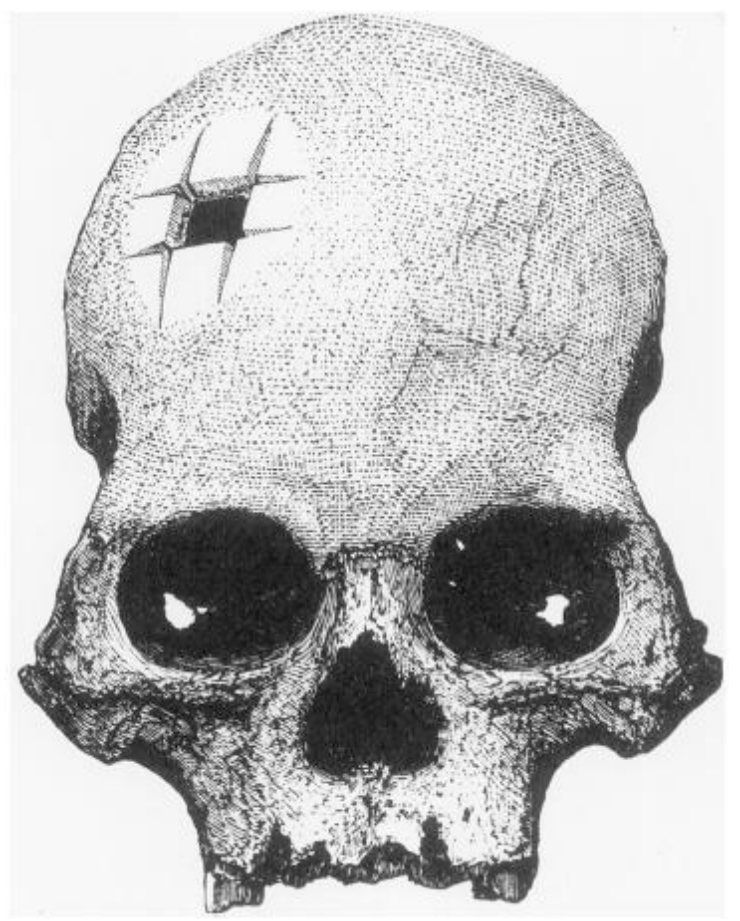

Figura 1. Crânio encontrado por Squier (1821-1888) em Cuzco, Peru, com um pequeno orifício retangular de $15 \mathrm{X} 17 \mathrm{~mm}$, datado por volta de $1500-1400$ a.C.

Para corroborar sua hipótese, Squier (1865) enviou o crânio para o então conceituado neurologista Paul Broca (1824-1880). Após minuciosa análise, Broca (1867) concluiu que de fato o orifício desse crânio era resultado de alguma "avançada cirurgia" realizada em uma pessoa ainda viva. Além disso, identificou sinais de inflamação, sugerindo que a pessoa teria morrido uma ou duas semanas após o procedimento cirúrgico (Clower \& Finger, 2001; Finger, 1994; Finger \& Fernando, 2001).

O crânio descoberto por Squier (1865) constitui um divisor de águas com relação a uma nova interpretação dos crânios trepanados descobertos em culturas pré-históricas (Andrushko \& Verano, 2008; Clower \& Finger, 2001; Finger, 1994; Finger \& Clower, 2001; Finger \& Fernando, 2001). Essa descoberta levou a uma busca por outros crânios trepanados produzidos por culturas préhistóricas. De fato, diversos crânios com as mesmas características foram identificados em sítios arqueológicos do período Neolítico na França, muitos deles datados de cerca de 4.000 a 5.000 anos (Clower \& Finger, 2001; Finger \& Fernando, 2001).

Acredita-se hoje que a trepanação surgiu de forma independente em diferentes culturas antigas, existentes desde o período Neolítico, há mais de 12 mil anos atrás, e, dessa forma, é considerado um dos procedimentos cirúrgicos mais antigos (Broca, 1867; Gerszten et al., 1998; Gross, 1999a, 1999b; Horsley, 1888; Lillie, 1998; Liu, \& Apuzzo, 2003; Marino-Junior \& Gonzales-Portillo, 2000; Persuad, 1984; Piek et al., 1999). Os orifícios cranianos feitos pelo homem pré-histórico variavam bastante de tamanho: desde alguns milímetros até metade de todo o crânio. As trepanações mais antigas eram realizadas por meio de repetidas raspagens do crânio, muito provavelmente com a utilização de pedras ou conchas afiadas. Culturas mais avançadas perfuravam o crânio realizando cortes bem mais precisos. Entre os mais comuns estavam os cortes arredondados, produzidos através de rotações manuais. Para essas cirurgias, tais culturas desenvolveram instrumentos específicos (Andrushko \& Verano, 2008; Blos, 2003; Clower \& Finger, 2001; Gross, 1999a, 1999b; Horsley, 1888; Lillie, 1998; Liu \& Apuzzo, 2003; Marino-Junior \& Gonzales-Portillo, 2000; Persuad, 1984).

Muito provavelmente a trepanação era realizada na ausência de qualquer assepsia, o que resultava em grande índice de infecção e, conseqüentemente, um índice elevado de óbito (Finger, 1994; Gross, 1999a; MarinoJunior \& Gonzales-Portillo, 2000). Entretanto, estudos mostram que cerca de $60 \%$ a $70 \%$ das pessoas submetidas à trepanação sobreviviam ao procedimento cirúrgico, indicando a presença de cuidados durante e após este (Blos, 2003; Marino-Junior \& Gonzales-Portillo, 2000; Ribas, 2006). Uma análise de crânios trepanados encontrados em onze sítios na região de Cuzco, no Peru, concluiu que a realização de trepanações com sucesso desenvolveu-se ao longo do tempo, com uma alta taxa de sobrevivência e baixa infecção pós-operatórias (Andrushko \& Verano, 2008).

A busca pelos motivos que justificariam a realização de trepanações pelo homem pré-histórico levou Broca a publicar diversos artigos e palestras sobre o assunto (Clower \& Finger, 2001; Finger, 1994; Finger \& Clower, 2001; Finger \& Fernando, 2001; Munro, 1891). Segundo ele, a trepanação era realizada principalmente em jovens, para o tratamento de convulsões simples associadas a possessões demoníacas. Dessa forma, Broca atribuiu uma função religiosa, propondo que a trepanação teria a capacidade de liberar demônios que estariam atormentando o doente (Clower \& Finger, 2001; Finger \& Clower, 2001; Finger \& Fernando, 2001; Munro, 1891).

Em oposição a essa perspectiva religiosa, Victor Horsley (1857-1916), neurocirurgião contemporâneo a Broca, excluiu o componente místico ou sobrenatural associado à trepanação entre as culturas primitivas. De acordo com Horsley, a cirurgia estaria relacionada exclusivamente ao tratamento de convulsões originárias de algum tipo de traumatismo craniano. Suas conclusões fundamentaram-se no fato de que os orifícios presentes nos crânios trepanados não estavam distribuídos de forma de forma aleatória, mas, na verdade, concentravam-se no ápice do crânio, acima do córtex motor primário, mais especificamente no giro pré-central (Clower \& Finger, 2001). 
A proposta de Horsley não foi bem recebida no meio científico da época. Por exemplo, Francis Galton (18221911) afirmou que a interpretação de Horsley "implica mais inteligência aos selvagens do que eles normalmente demonstram" (como citado em Clower \& Finger, 2001). Atualmente, consideram-se complementares a visão empírica de Horsley, que analisa os dados em relação aos crânios trepanados, e a abordagem mais antropológica de Broca, que procurou associar possíveis convulsões em jovens com explicações místico-religiosas. Assim, a prática da trepanação teria finalidades desde mágico-religiosas a exclusivamente terapêuticas, nesse caso no tratamento de epilepsia, dor de cabeça e sintomas relacionados com traumatismo craniano (Clower \& Finger, 2001; Finger \& Clower, 2001; Finger \& Fernando, 2001; Ribas, 2006).

Em consonância com essa perspectiva complementar, evidências indiretas das possíveis causas da prática da trepanação podem ser encontradas em diversas tribos que ainda praticam esse procedimento nos dias atuais. De acordo com Finger e Clower (2001), tribos de ilhas do Pacífico Sul ainda realizam a trepanação no tratamento de fraturas, epilepsia, loucura e dores de cabeça. No Quênia, trepanações eram usadas até recentemente no tratamento de dores de cabeça, com ou sem fraturas cranianas. De forma semelhante, dores de cabeças e traumatismos cranianos também eram tratados por meio de trepanação na Uganda, Nigéria, Somália, Líbia e entre os Zulus na África de Sul.

Do ponto de vista cirúrgico, deve-se observar que a realização, no passado, de trepanações exigia um conhecimento anatômico do crânio, uma vez que remoções ósseas extensas e bilaterais eram freqüentemente realizadas com a preservação da porção óssea mediana que cobre o seio sagital superior, importante via de drenagem venosa dos hemisférios cerebrais (Gross, 1999a). O emprego dessa técnica por culturas pré-históricas, seja com fins exclusivamente terapêuticos ou com fins religiosos, sugere que o homem pré-histórico já atribuía um papel importante ao cérebro, ou ao menos à região da cabeça, na regulação de funções mentais superiores (Blos, 2003; Finger, 1994; Gross, 1998, 1999a).

Finalmente, deve-se mencionar que a trepanação, em culturas pré-históricas, era também praticada após a morte, uma vez que alguns desses crânios não apresentavam qualquer cicatrização. Existe o consenso de que os fragmentos cranianos retirados após a morte de uma pessoa eram utilizados provavelmente como uma espécie de amuleto (Clower \& Finger, 2001; Finger \& Clower, 2001; Finger \& Fernando, 2001). Muitos crânios trepanados, sem qualquer sinal de cicatrização foram encontrados em locais de batalha. Esses amuletos poderiam servir como um sinal de status de guerreiros ou líderes de culturas pré-históricas (Blos, 2003; Clower \& Finger, 2001; Finger \& Clower, 2001; Finger \& Fernando, 2001; Ribas, 2006).

\section{O Egito e os Primeiros Registros do Cérebro e a Importância do Coração}

Se podemos apenas inferir que importância o homem primitivo dava ao cérebro humano através da análise de seus crânios, com o surgimento da escrita essas inferências se tornam muito mais precisas. $\mathrm{O}$ registro escrito mais antigo referente à palavra "cérebro" encontra-se em um papiro egípcio médico, datado em 1700 a.C., mas que aparentemente é uma cópia de outro texto, relacionado a um período muito anterior, provavelmente de cerca de 3000-2500 a.C. (Finger, 2000; Gross, 1998). Embora não se conheça com certeza o autor desse texto mais antigo, atribui-se sua autoria ao médico egípcio Imhotep, que provavelmente viveu na III Dinastia do Império Antigo (referente ao período de 2690 e 2670 a.C.), servindo ao Faraó Zoser. Em sua homenagem, foram erguidos templos em Mênfis e em outras localidades, onde os enfermos podiam rezar e receber tratamento médico. Além de médico, Imhotep foi arquiteto, sacerdote e astrônomo. Sua reputação era tão grande entre os egípcios que foi deificado, considerado patrono da escrita, do conhecimento em geral e da medicina. Posteriormente, foi reconhecido pelos gregos como o deus Asclépio (El Gindi, 2002; Feldman \& Goodrich, 1999; Finger, 2000; Krivoy, Krivoy, \& Krivoy, 2002; Martín-Araguz, BustamanteMartínez, Emam-Mansour, \& Moreno-Martínez, 2002; Puigbó, 2002).

O papiro, datado em 1700 a.C., foi descoberto em 1862, mas permaneceu inédito até 1930, quando o egiptólogo James Breasted publicou uma extensa tradução comentada de seu conteúdo. Atualmente, esse papiro é conhecido como "Papiro cirúrgico de Edwin Smith". Medindo cerca de $4,5 \mathrm{~m}$ de largura e $33 \mathrm{~cm}$ de altura, esse papiro é composto por 48 casos clínicos, descritos sistematicamente, iniciando pela cabeça e descendo pelo tórax e pela espinha, onde o documento é interrompido. Cada caso apresenta um título, descrição clínica do caso, diagnóstico e um glossário que busca esclarecer os termos técnicos. Além disso, cada caso é classificado de acordo com uma escala de severidade de três pontos: "um mal que irei tratar"; "um mal que irei combater"; e "um mal que não deve ser tratado" (Feldman \& Goodrich, 1999; Finger, 2000; Krivoy et al., 2002; Puigbó, 2002; Wilkins, 1964).

Entre os 48 casos descritos, 27 estão relacionados com algum traumatismo direto à cabeça. Apenas 13 deles apresentam uma real evidência de dano cerebral, com anormalidades neurológicas e fraturas cranianas. Além disso, são encontradas no papiro referências diretas ao cérebro, citado sete vezes ao todo, assim como às meninges e ao líquido cefalorraquidiano, além de uma descrição dos giros corticais como "enrugamentos formados como cobre derretido" (Finger, 2000; Martín-Araguz et al., 2002; Wilkins, 1964).

A descrição de casos de lesões na cabeça indica que os antigos egípcios já reconheciam que danos no sistema 
nervoso central poderiam ter efeitos em áreas distantes do ferimento (Finger, 2000). Entretanto, consideravam o coração, e não o cérebro, como o centro do corpo e a sede da alma/mente. A alma, denominada " $b a$ ", era considerada como uma entidade invisível e imortal que seria julgada após a morte do corpo pelos seus atos durante a vida. De acordo com essa cultura, o coração seria capaz de armazenar todas as informações e experiências que uma pessoa teria adquirido em toda a vida. Na morte, o coração seria pesado contra uma pluma e, conforme seu peso, a pessoa seria julgada culpada ou inocente (Boisaudin, 1988; Finger, 1994, 2000).
A Figura 2 apresenta uma ilustração de um morto sendo trazido por Anúbis, deus da mumificação, para a pesagem de seu coração. Durante a cerimônia, decidiase se o morto seria mandado para o paraíso ou serviria de alimento para a figura mitológica, semelhante a um crocodilo, chamada de Devorador de Almas. Na imagem, ao lado direito do Devorador, encontra-se Thot, deus da Sabedoria. À sua direita, está Hórus, deus do Céu. Sentado à direita, Osíris, deus do Mundo Subterrâneo. Essa imagem é conhecida como "O Julgamento Perante Osíris", do "Livro dos Mortos" (1285 a.C.).

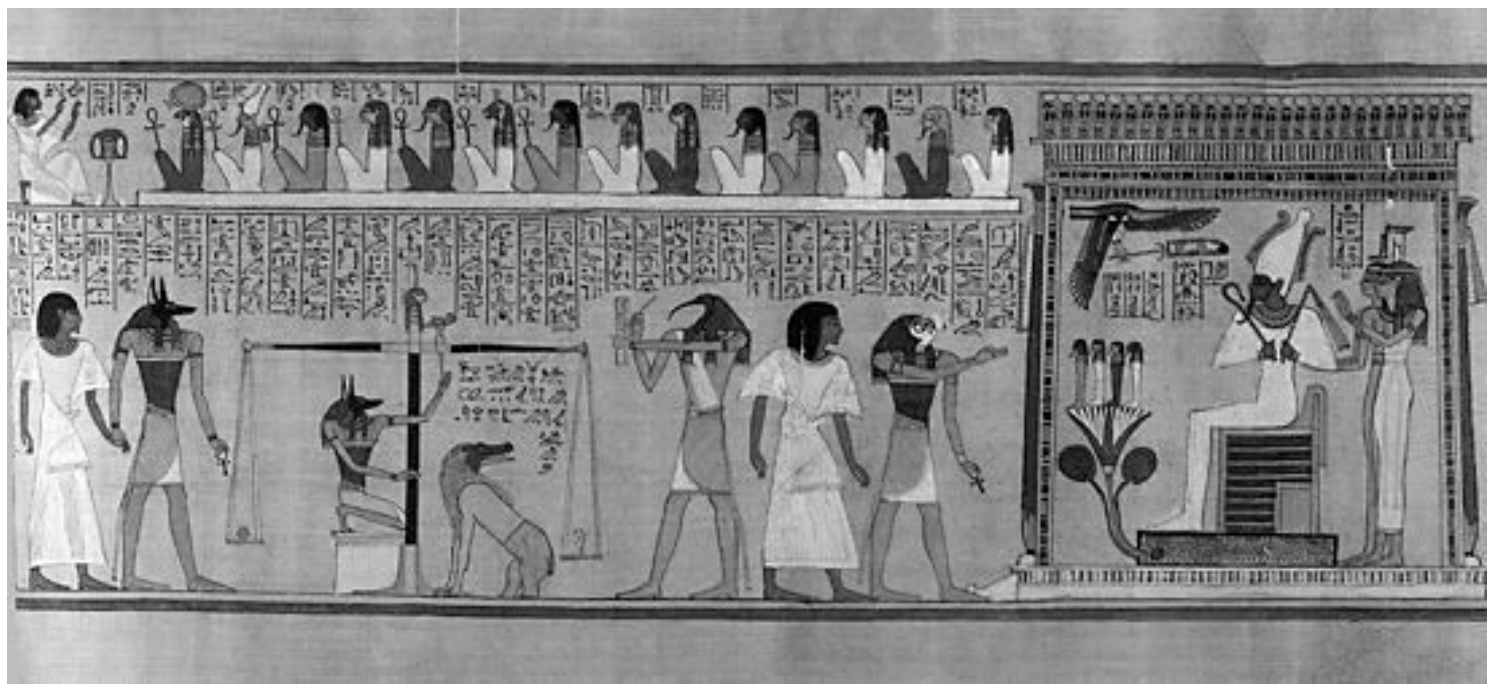

Figura 2. Ilustração "O julgamento perante Osíris", do "Livro dos Mortos" (1285 a.C.)

Para os antigos egípcios, a alma (" $b a$ "), após a morte, precisaria de um corpo para habitar. Daí a necessidade da mumificação. Nesse processo, o coração permanecia no corpo, uma vez que era um órgão de excelência. $\mathrm{O}$ cérebro, por outro lado, era tratado com indiferença. Sua remoção era feita através da inserção de um instrumento em forma de gancho através do nariz. O instrumento macerava o material do cérebro que era rapidamente liquefeito, drenado para fora do crânio e depois descartado (Finger, 2000).

$\mathrm{Na}$ verdade, o coração era considerado o órgão responsável pelo pensamento, pelas emoções e por todas as demais funções hoje associadas ao sistema nervoso central (Boisaudin, 1988; Finger, 2000; Willerson \& Teaff, 1996). Por essa razão, os antigos egípcios acreditavam que o coração era o centro do organismo e estaria conectado com os demais órgãos do corpo através de uma rede de canais, chamados de "metu". Essa rede seria formada por 36 canais, que partiriam do coração, onde não haveria apenas sangue, mas também ar, lágrimas, saliva, muco, sêmen, comida, urina etc. Assim, não só os vasos sanguíneos eram considerados "metu", mas também o trato respiratório, os dutos glandulares e os músculos. Conseqüentemente, não era feita distinção entre artérias, veias, tendões, nervos ou ligamentos (Boisaudin, 1988; Willerson \& Teaff, 1996).

Os antigos egípcios atribuíam a origem das enfermidades ao efeito de feitiçaria, encantos ou espíritos malignos. Para eles, os espíritos malignos causadores das enfermidades entrariam no corpo da pessoa através dos orifícios, como ouvido, nariz e boca, e se espalhariam por todo o organismo por meio dos canais (metu), podendo eventualmente se concentrar em determinado órgão (Boisaudin, 1988; Martín-Araguz et al., 2002). Muitas vezes, o tratamento consistia, basicamente, na expulsão desses espíritos através de encantamentos e invocações das forças dos deuses, associados às poções. Se uma doença fosse controlada com sucesso, isso significava que o espírito maligno tinha sido expulso do organismo por algum orifício (Finger, 1994; Gross, 1998; Martín-Araguz et al., 2002).

Deve-se reconhecer, entretanto, que os antigos egípcios demonstraram também a preocupação em descrever algumas doenças de forma exclusivamente racional. Por exemplo, um papiro médico datado de cerca de 1500 a.C (papiro de Ebers) contém a descrição de um transtorno emocional que seria mais tarde denominado de histeria na Grécia Antiga, associado ao movimento do 
útero exercendo pressão sobre o diafragma e produzindo uma série de sintomas físicos e mentais (Nasser, 1987).

\section{A Mesopotâmia e a Prática Médica}

A área da Antiga Mesopotâmia é a região localizada entre os rios Tigre e Eufrates, no sudoeste da Ásia. Embora seus limites variassem durante diferentes períodos da história, de modo geral a região da Mesopotâmia abrangia o território do atual Iraque e parte da Síria. Muitos grupos étnicos dominaram sucessivamente essa região em diferentes períodos, como os sumérios, os assírios e os babilônicos (Oppenheim, 1964).

Um dos primeiros povos que ocupou essa região foram os sumérios, por volta de 3500 a.C. Eles construíram ali as primeiras grandes cidades da civilização humana, como Ur, Uruk e Lagash (Oppenheim, 1964). Atribui-se a eles o desenvolvimento, por volta de 4000-3500 a.C., da escrita cuneiforme, na qual os símbolos eram cunhados em placas de barro. Desenvolvida inicialmente para escrever a língua suméria, a escrita cuneiforme foi adotada por outros povos que se assentaram posteriormente nessa região, como os assírios e os babilônicos. A essência da cultura suméria manteve-se mesmo após a desintegração do Estado sumério. Pode-se, por isso, apesar da grande diversidade dos grupos étnicos, falar em uma civilização mesopotâmica.

Devido à escassez de evidências arqueológicas, muitas informações que possuímos atualmente sobre os povos mesopotâmicos são provenientes dos tabletes de escrita cuneiforme, utilizados para os registros administrativos, econômicos, culturais e políticos da época (Kinnier \& Reynolds, 1990; Moore, 1988; Oppenheim, 1964; Saggs, 1965; Spiegel \& Springer, 1997). Apesar da abundante quantidade desses tabletes, poucos tratam do entendimento que seus autores tinham sobre o corpo, a mente (ou alma) humana e a relação entre eles. Grande parte dos tabletes referentes a esses assuntos encontram-se na biblioteca de Assurbanipal, o último grande rei da Assíria (Birchette, 1973).

Assim como entre os antigos egípcios, a etiologia da enfermidade, tanto física quanto mental, estava, no caso dos mesopotâmicos, associada diretamente a um pensamento sobrenatural. Deste modo, a patologia estava intimamente associada à ação dos deuses. Quando estes deixavam de proteger uma pessoa, ela ficava à mercê da ação de demônios e/ou espíritos malignos, que poderiam agir sobre seu corpo e/ou mente. Por essa razão, tanto a doença quanto a curam era explicadas a partir de uma complexa relação entre deuses, seres humanos e espíritos que assombrariam os vivos (Biggs, 1995; Finger, 1994; Oppenheim, 1964; Scurlock, 1995; Stol, 1992).

Os povos da Antiga Mesopotâmia adotavam um sistema médico empírico, que consistia basicamente em uma longa lista dos sintomas, associados a determinados espíritos/demônios. Identificado o demônio/espírito maligno responsável por aquela doença, o tratamento era exe- cutado, e consistia basicamente de rituais de exorcismo ou do uso de misturas de ervas associadas a encantos. As prescrições médicas mais antigas encontradas na Antiga Mesopotâmia, escritas na língua suméria, datam da Terceira Dinastia de Ur - cerca de 2000 a.C. (Saggs, 1965).

A doença estava sempre associada a uma transgressão, motivo pelo qual os deuses teriam abandonado o transgressor. Poderia existir uma exceção a essa regra, ou seja, quando a doença se expressava na ausência de uma transgressão. Nesse caso, a etiologia da doença transcendia a compreensão humana. Dessa forma, o principal objetivo do diagnóstico seria descobrir as transgressões cometidas pelo enfermo e qual espírito/demônio se apoderara de seu corpo. Essa investigação era realizada por meio de um longo interrogatório, bem como pelo uso de técnicas de adivinhação, calcadas na astrologia e na hepatoscopia, inspeção do fígado de animais - especialmente ovelhas - em busca de sinais reveladores dos deuses. Diversas culturas já utilizavam a investigação de vísceras como uma forma de identificar os sinais dos deuses. Mas foram os povos mesopotâmicos que utilizaram a hepatoscopia de forma sistemática para obter o diagnóstico de uma doença.

A Figura 3 apresenta um exemplo de um modelo em argila do fígado de um carneiro encontrado na Babilônia, medindo $6 \mathrm{~cm}$ e datado de aproximadamente 2050-1740 a.C. Pedaços de madeira seriam colocados nos buracos do modelo, como lembretes das características encontradas no fígado analisado. Acredita-se que esses modelos em argila eram utilizados no ensino dos jovens sacerdotes na arte da hepatoscopia.

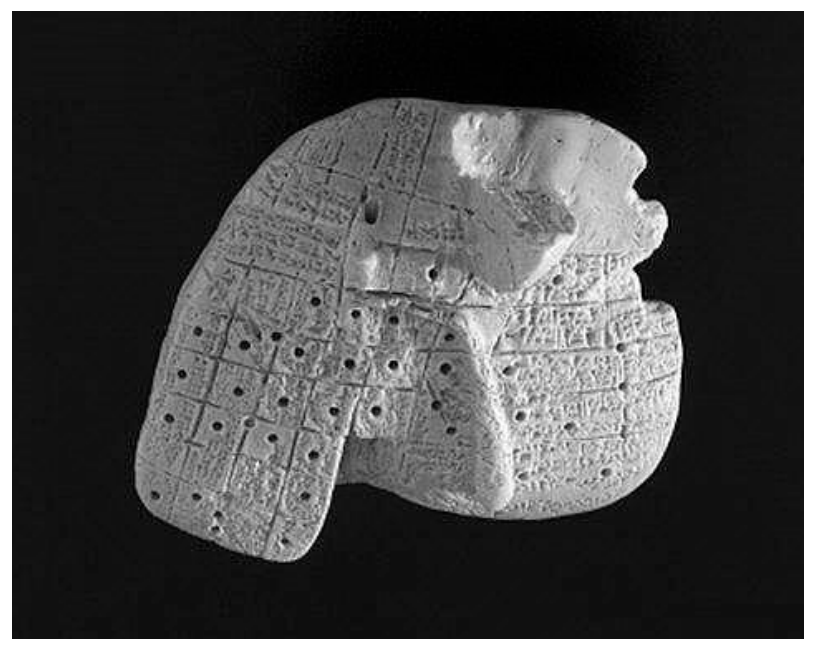

Figura 3. Modelo em argila do fígado de um carneiro encontrado na Babilônia, medindo $6 \mathrm{~cm}$ e datado de aproximadamente 2050 a.C. a 1740 a.C.

A escolha do fígado como órgão em que os deuses expressavam suas vontades parece estar relacionada com a importância que os antigos mesopotâmicos atribuíam a esse órgão. De acordo com Reuben (2004), o fígado era considerado a "sede da vida" e, em conseqüência, "a sede 
da alma”. Não há, nos registros deixados pelos mesopotâmicos, qualquer referência ao coração como um órgão de excelência para as funções vitais humanas.

A Antiga Mesopotâmia apresentava duas figuras distintas para prover a saúde de sua população. O primeiro deles era o sacerdote, chamado de "ashipu" (ou "asipu"), responsável por identificar os sintomas e descobrir que espírito era responsável pela etiologia da doença. Eram eles que realizavam o longo interrogatório, além de utilizar técnicas adivinhatórias. Além do "ashipu", existia também uma figura muito próxima ao nosso conceito de médico, chamado "ashu" (ou "asu"). Este seria responsável pela prescrição de ervas e/ ou poções, associadas a encantamentos e orações, com o objetivo de tratar a enfermidade. Embora essas duas figuras apresentassem atividades específicas, podia ocorrer uma interação entre elas. De fato, "ashu" e "ashipu" trabalhavam lado a lado no atendimento de uma mesma enfermidade, não existindo qualquer hierarquia entre ambos. Deve-se destacar, entretanto, que a figura do "ashipu", por ser um sacerdote, tinha outras funções religiosas, ao passo que a figura do " $a s h u$ " restringia-se à função médica (Adamson, 1991; Biggs, 1995; Spiegel \& Springer, 1997).

Pelo fato de a doença estar sempre associada a fenômenos sobrenaturais, não existia qualquer distinção entre doenças físicas e mentais. Por exemplo, a epilepsia, muito bem descrita em uma coleção de tabletes datados de 718-612 a.C., era interpretada como a manifestação da ação de demônios (Kinnier \& Reynolds, 1990). Na verdade, esses povos apresentavam pouco conhecimento de anatomia humana, muito provavelmente restritos a analogias feitas a partir do interior do corpo de outros animais, particularmente a ovelha, devido à prática de hepatoscopia (Biggs, 1995; Moodie, 1917; Spiegel \& Springer, 1997). Não foram encontradas informações sobre a prática de cirurgias e, até onde se sabe, não eram realizadas dissecações humanas (Adamson, 1991; Spiegel \& Springer, 1997). Suturas e amputações de membros eram realizadas por uma terceira figura, denominada "gallabu", cuja função se assemelhava à do cirurgiãobarbeiro da Idade Média, sem qualquer especialização em técnicas cirúrgicas. Nesse sentido, o conhecimento dos egípcios em relação à anatomia humana era muito mais extenso, assim como suas habilidades cirúrgicas (Adamson, 1991; Moodie, 1917; Spiegel \& Springer, 1997).

\section{A Índia e a Relação Entre o Micro e o Macro Universo}

Observa-se na Índia Antiga o desenvolvimento de um corpo filosófico-religioso extremamente complexo e bem elaborado, onde conceitos sobre mente, corpo e universo se misturam. Para Carvalho (1996), a antiga civilização indiana desenvolveu uma das teorias da mente mais antiga da qual se tem conhecimento.
Os primeiros registros escritos sobre a cultura e a organização social e religiosa da Índia Antiga datam por volta de 2000 a.C. (Kak, 1997a, 1997b). Esses textos, denominados "Vedas", que em sânscrito significa "conhecimento", podem ser considerados a materialização escrita de uma tradição oral anterior. Dessa forma, esses textos expressam um conhecimento bem mais antigo, cujas evidências arqueológicas apontam para uma origem em torno de 3000 a.C. (Kak, 1997a, 1997b).

Os textos "Vedas" fundamentam todo o conhecimento indiano antigo. A interpretação de um desses textos, o "Atharva Veda", serve como ponto de origem de uma prática médica bem sistematizada, denominada de "Ayurveda", termo que, em sânscrito, significa "conhecimento da vida". A medicina ayurvédica surge como um denso sistema teórico com o intuito de compreender a mente e a sua relação com o corpo e o mundo exterior. O Ayurveda representa a convergência de crenças mágicoreligiosas com observações empíricas, adquiridas posteriormente.

O conhecimento ayurvédico desenvolvido a partir dos Vedas foi sistematizado em dois tratados médicos. O primeiro deles, escrito em torno de 250 a.C., denominado "Charaka Samhita", em referência ao médico indiano Charaka, apresenta os princípios fundamentais do tratamento ayurvédico e, ainda, como era a compreensão dada ao corpo humano em sua época (Menon \& Haberman, 1969; Rao, 1968). O segundo deles, escrito em torno de 150 a.C., denominado "Susruta Samhita", em referência ao médico indiano Susruta, apresenta princípios cirúrgicos e anatômicos da época, bom como princípios da formação médica (Menon \& Haberman, 1969; Rao, 1968; Subbarayappa, 2001). Nesse segundo texto, enfatizavase a prática da dissecação. Embora superficial, ela era fundamental para o conhecimento do corpo humano. Além disso, limitava-se ao estudo dos corpos de crianças de até dois anos, uma vez que a civilização indiana cremava todos os mortos acima de cinco anos de idade (Moodie, 1917; Subbarayappa, 2001).

De acordo com a perspectiva ayurvédica, existe uma relação direta entre o homem (microcosmos) e o universo (macrocosmos) (Kak, 1997a; Subbarayappa, 2001). Essa concepção de interação entre elementos básicos que formam o indivíduo e o universo que o cerca está calcada no pensamento filosófico-religioso indiano, chamado "Samkhya", que teve origem na antiga cultura indiana, aproximadamente em 700-500 a.C. A compreensão desse sistema filosófico-religioso é fundamental para o entendimento da prática médica ayurvédica e, conseqüentemente, da interação entre mente, corpo e mundo externo.

De acordo com o Samkhya, o universo tem origem a partir da interação entre dois princípios metafísicos: a "Consciência Pura" ou "Alma imaterial", denominada "Purusha", e "Matéria Original Pura", denominada "Prakriti". A palavra "pura" presente nesses dois princípios metafísicos reflete seus estados indiferenciados, 
indicando assim a ausência de uma forma bem definida. A experiência subjetiva do mundo externo e o próprio universo seria conseqüência da interação desses dois princípios. Após esse processo de interação, teria início outro princípio, denominado "Buddhi", traduzido como "intelecto", responsável pelo processamento sensorial, organização e interpretação dos objetos do mundo externo. Dessa forma, a presença de um determinado objeto no mundo externo depende da percepção desse objeto pela consciência humana. Essa concepção da mente humana antecipa uma grande variedade de concepções sobre a mente humana propostas a partir da filosofia moderna.
De acordo com o Samkhya, todos os objetos do mundo externo são compostos por cinco elementos básicos: éter, fogo, terra, água e ar. Cada um desses elementos estaria associado a um órgão sensorial: nariz, olhos, pele, língua e ouvidos; que por sua vez dariam origem a sensações específicas: som, toque, cheiro, cor e/ou forma e sabor. Essas sensações são consideradas elementos sensíveis da percepção, capazes de representar cada um desses elementos básicos na mente humana. Da mesma forma, cada um desses cinco elementos básicos estaria também associado um determinado órgão motor: mãos, pés, voz, órgãos reprodutivos e de excreção, responsáveis pela ação do sujeito no mundo. Essas relações estão representadas na Tabela 1.

Tabela 1

Relação entre os Elementos Básicos, as Sensações Específicas, os Órgãos Sensoriais e os Órgãos Motores e de Ação do Sujeito sobre o Mundo, de acordo com a Civilização da Índia Antiga

\begin{tabular}{cccccc}
\hline $\begin{array}{c}\text { Elementos } \\
\text { Básicos }\end{array}$ & $\begin{array}{c}\text { Objetos dos } \\
\text { Sentidos }\end{array}$ & $\begin{array}{c}\text { Faculdades } \\
\text { Sensoriais }\end{array}$ & $\begin{array}{c}\text { Órgãos } \\
\text { Sensoriais }\end{array}$ & $\begin{array}{c}\text { Faculdades } \\
\text { de Ação }\end{array}$ & $\begin{array}{c}\text { Órgãos } \\
\text { Motores }\end{array}$ \\
\hline Éter & Som & Audição & Ouvidos & Fala & Cordas Vocais \\
Ar & Toque & Percepção Tátil & Pele & Dar e Receber & Mãos \\
Fogo & Forma & Visão & Olhos & Andar & Pernas \\
Água & Sabor & Paladar & Língua & Procriação & Genitálias \\
Terra & Cheiro & Olfato & Nariz & Oxcrãa & Órgãos Excretores \\
\hline
\end{tabular}

Em suma, é a partir da interação de uma entidade imaterial e de uma matéria indiferenciada da primeira que surge um princípio organizador. Desse princípio organizador o mundo externo emerge, pela percepção dos cinco elementos básicos através das cinco sensações, produtos dos cinco órgãos sensoriais e que possibilitam a interação com o mundo externo através de cinco órgãos motores.

Com base nesse pensamento filosófico-religioso do Samkhya, a prática médica indiana ayurvédica entende o ser humano como um microcosmo da natureza e, portanto, composto pelos mesmos cinco elementos básicos citados antes. No corpo, os espaços, como a boca, o trato gastrintestinal e o respiratório, eram vistos como a representação do éter (ou "Akasha"). O ar ("Vaya"), elemento do movimento, estaria presente na pulsação do coração e nos movimentos dos pulmões. O fogo ("Tejas") seria responsável pelo metabolismo, agindo na digestão dos alimentos no estômago, ao mesmo tempo em que seria responsável pela ativação da retina para percebermos a luz. A água ("Apa") se manifestaria nas secreções e mucosas do corpo em geral, sendo vital para o funcionamento do corpo. Da terra ("Prithvi") seriam derivadas todas as estruturas sólidas derivadas existentes no corpo (Kak, 1997a; Lyssenko, 2004; Subbarayappa, 2001).

Da mesma forma, os cinco elementos básicos são os objetos dos sentidos e é por eles que o mundo pode ser percebido. Têm, dessa forma, uma relação funcional tanto com os órgãos sensoriais quanto com aqueles órgãos que nos permitem responder aos estímulos sensoriais. Por exemplo, o sabor dos alimentos surge a partir das diferentes combinações dos cinco elementos básicos no alimento (Lad, 2001; Subbarayappa, 2001). Além disso, é pela interação desses cinco elementos que se manifestam três forças vitais, chamadas de "doshas", termo geralmente traduzido como "humores" (Lad, 2001).

Assim, toda a realidade pode ser reduzida aos cinco elementos que, quando combinados, geram três forças vitais, o tridosha. É a partir da compreensão do ser humano como sendo composto, tanto física quanto psicologicamente, pelas três forças vitais ou humores é que se organizam os fundamentos da anatomia, fisiopatologia e farmacologia ayurvédica (Lad, 2001; Subbarayappa, 2001).

Essas forças vitais ou humores participam da formação da natureza humana desde o seu nascimento. De acordo com essa perspectiva, uma pessoa, logo ao nascer, teria uma concentração própria de cada uma dessas três forças. A constituição individual, chamada de "Prakriti", palavra também entendida como "constituição inicial", em sânscrito, seria determinada através das diferentes concentrações de cada uma dessas três forças vitais (tridosha) no momento do nascimento, ocorrendo, geralmente, o predomínio de uma delas. Para a Ayurveda, a constituição inicial (Prakriti) permaneceria imutável durante o curso da vida da pessoa e serviria de base para 
o desenvolvimento de características físicas, necessidades naturais, gostos e desgostos, predileções psicológicas, assim como para as tendências individuais de saúde (Subbarayappa, 2001). A saúde seria entendida como um estado de equilíbrio das concentrações naturais individuais das três forças vitais no organismo. Consequientemente, o processo de adoecer estaria associado com a perda desse equilíbrio (Subbarayappa, 2001).

Além dessas três forças vitais ("tridosha"), o corpo também é composto fisicamente pelos tecidos denominados de "dhatus" (em sânscrito, "aquilo que forma o corpo"). Dessa forma, eles dividiam o corpo em intestino ("Rasa Dhatu"); sangue ("Rakta Dhatu"); tecidos musculares ("Mamsa Dhatu"); gordura ("Meda Dhatus"); ossos ("Asthi Dhatu"); tecidos reprodutivos ("Shukral Artava Dhatu"); e o conjunto formado por medula óssea, medula espinhal e encéfalo ("Majja Dhatu"). Vale a pena ressaltar o fato de se considerarem o cérebro e a medula espinhal como um tecido igual à medula óssea. Isso provavelmente se deve ao fato de todos esses tecidos encontrarem-se no interior do osso: medula espinhal dentro do canal vertebral e o encéfalo dentro do crânio.

No "Susruta Samhita" é feita a descrição dos quatro pares de nervos cranianos: dois nervos chamados "Nila" e "Manya", situados ao lado da laringe e que, quando danificados, produzem perda ou mudança da voz; um par de nervos chamados "Vidhura", atrás das orelhas, associados com a audição; um par de nervos chamados "Phana", situados dentro do nariz e associados ao olfato; e um par de nervos chamados "Apanga", situados abaixo dos olhos, associados à visão (Rajgopal, Hoskeri, Bhuiyan, \& Shyamkishore, 2002).

Apesar de uma relativa organização do conhecimento na Índia Antiga, existem relatos pontuais a respeito da estrutura e da função do sistema nervoso e mais especificamente sobre as funções do cérebro. De acordo com o médico Bhela (datado por volta alguns séculos a.C.), autor do "Bhela Samhita" (do qual há apenas um manuscrito incompleto), seria o cérebro o centro das funções mentais (Prioreschi, 1995; Rajgopal et al., 2002). Entretanto, pouco se sabe sobre esse médico e muitas das narrativas referentes a ele estão misturadas com narrativas míticas ou com sua língua original, dificultando o acesso à informação. Por essa razão, sua datação é tarefa árdua. Sabe-se que, apesar disso, a visão predominante na Índia Antiga era a de que o coração seria a sede da alma (ou mente), graças à sua posição central no corpo humano (Rajgopal et al., 2002).

\section{A China e a Busca do Equilíbrio Entre Forças Opostas}

A Antiga China constitui um dos mais antigos centros de organização e cultura humana. Assim como o Egito, Mesopotâmia e a Índia, a antiga civilização chinesa estabeleceu-se ao longo do vale de um rio. E, de forma semelhante a estes povos, os chineses também desenvol- veram um sistema de escrita independente. Seus registros mais antigos datam do período da dinastia Shang (1700 a.C. a 1025 a.C.). Entretanto, estabelecer uma história da China Antiga é uma tarefa complexa, pois as narrativas e os registros feitos pelo povo chinês que descrevem os eventos ocorridos no passado diferem em alguns pontos das evidências arqueológicas encontradas.

Da mesma forma que as primeiras civilizações antigas, a origem e o desenvolvimento da medicina na Antiga China estão calcados em um sistema filosófico-religioso. A denominada Medicina Tradicional Chinesa (MTC) tem suas origens antes do período da dinastia Xia (2000 a.C. a 1700 a.C.) e apresenta uma íntima associação com conceitos metafísicos do Taoísmo e do Confucionismo. De acordo com o Taoísmo, o homem é produto da natureza. A concepção chinesa, desenvolvida a partir da observação dos ciclos e mudanças da natureza, considera que o universo e o ser humano estão submetidos às mesmas influências, sendo, portanto, partes integrantes do universo como um todo. Da mesma forma que na civilização da Índia Antiga, o corpo humano é visto como uma representação em miniatura do universo e, por isso, é regido pelas mesmas leis. A saúde era vista como um estado de equilíbrio harmônico das diversas formas de energia da natureza, presentes em todos os órgãos internos, glândulas e sistemas orgânicos (Méndez et al., 2001; Subbarayappa, 2001).

De maneira mais específica, a civilização da China Antiga refere-se ao universo, seja ele micro ou macro, como resultante entre Yin e Yang: duas forças opostas e equilibradoras de extremos cíclicos de tudo o que existe na natureza, tal como o dia e a noite; o inverno e o verão; o quente e o frio; o feminino e o masculino; o sono e a vigília. Essas duas forças básicas estariam em constante movimento e transformação, numa tentativa de manter o equilíbrio como um todo. Além disso, os chineses consideravam que a natureza é composta por cinco elementos básicos: terra, fogo, madeira, água e metal Esses cinco elementos seriam a base da constituição de tudo que existe na natureza, animada ou inanimada, e seriam fundamentais na manutenção e modificação desse equilíbrio de forças (Ehling, 2001; Subbarayappa, 2001; Wu, Davis, \& Po-Wang, 1932).

Conseqüentemente, o corpo humano também seria constituído por esses cinco elementos básicos e estaria sujeito às forças opostas Yin e Yang. Assim, a MTC baseia-se na idéia de que o ser humano é um microcosmo que constantemente interage com o universo que controla e influencia sua vida, incluindo sua saúde. A enfermidade seria então produto do desequilíbrio entre essas duas forças opostas.

Assim como outros aspectos na cultura chinesa, os registros antigos que servem como fontes de informação sobre o conhecimento da época geralmente estão associados a personagens míticos. De acordo com a história tradicional chinesa, a arte da cura teve início com a figu- 
ra mítica de Huang Di, conhecido como o "Imperador Amarelo" (2698 a.C.-2599 a.C.). Uma das principais fontes de informação acerca do conhecimento do corpo humano e do pensamento chinês antigo encontra-se no antigo texto clássico "Huang Di Nei Jing", atribuído a Huang Di. Embora o texto tenha sido compilado por volta de 2500 a.C., não foi registrado até a dinastia Zhou, por volta de 1066 a.C. a 221 a.C. Fragmentos desse documento são atualmente datados por volta de 475 a.C. a 221 a.C. (Hong, 2004; Moodie, 1917).

O texto tem a forma de um diálogo entre Huang Di e seu companheiro médico Qi Bo, no qual discutem diversos assuntos, como saúde e nutrição, prevenção de doenças, diagnóstico, acupuntura e outros assuntos médicos. Além disso, o texto é dividido em duas partes: o "Su Wen", que enfatiza o pensamento filosófico chinês por trás da prática médica, assim como explicita as teorias e princípios da medicina chinesa; e o "Ling Shu", que é mais focado em técnicas específicas de acupuntura, teoria dos meridianos e a descrição de várias agulhas de acupuntura (Hong, 2004).

É no "Huang Di Nei Jing" que se encontra uma descrição mais específica das diversas regiões corporais. Os órgãos internos são denominados de "Zang $F u$ " e divididos em dois grupos: os "Zang", que incluem coração, fígado, baço, pulmão e rins; e as vísceras, denominadas " $F u$ " (Ehling, 2001; Finger, 1994; Hong, 2004). Cada um dos cinco órgãos "Zang" (coração, fígado, baço, pulmão e rins) está associado a um dos cinco elementos básicos da natureza (fogo, madeira, terra, o metal e a água). Esses elementos básicos, por sua vez, estão associados a uma emoção específica: alegria, melancolia, apreensão, tristeza e medo, respectivamente. Essas relações são apresentadas na Tabela 2.

\section{Tabela 2}

Relação entre os Cinco Elementos Básicos da Natureza, os Órgãos e as Emoções que se Associam entre Eles, de acordo com a Civilização da China Antiga

\begin{tabular}{ccc}
\hline Órgãos & Elementos & Emoções \\
\hline Coração & Fogo & Alegria \\
Fígado & Madeira & Melancolia \\
Baço & Terra & Apreensão \\
Pulmão & Metal & Tristeza \\
Rins & Água & Medo \\
\hline
\end{tabular}

Já os órgãos " $F u$ " eram interpretados como órgãos auxiliares. Nesse grupo estão os intestinos, o estômago, a vesícula biliar e a bexiga. Além disso, para os antigos chineses, o cérebro era considerado um órgão peculiar, denominado "mar da medula", e não estava associado a nenhuma função mental (Ehling, 2001). De fato, era o coração, e não o cérebro, o órgão associado à emoção e à cognição humanas (Ehling, 2001).
Apesar do crescente interesse ocidental sobre a MTC, os textos médicos tradicionais chineses, com algumas exceções, só estão disponíveis em poucas línguas ocidentais. Por isso, a obtenção de informações concretas, na execução de um trabalho sério de pesquisa visando a comparação com as correntes de pensamento de outras culturas, fica limitado àquelas pessoas que podem ler os textos originais. Assim como outros aspectos na cultura chinesa, os autores dos textos clássicos têm sido associados a personagens místicas e situados em um passado remoto, o que dificulta ainda mais a separação de fatos reais e mitologia.

\section{Considerações Finais}

A mente humana sempre provocou fascínio ao longo da história da humanidade. Assim como navegadores desbravando mares desconhecidos, cientistas e filósofos têm procurado - ontem e hoje - desvendar as águas profundas da mente humana e sua relação (direta ou indireta) com o funcionamento cerebral. Aqui, pudemos observar algumas dessas investidas em busca de respostas a respeito da natureza humana ainda em um período remoto, quando a produção de conhecimento apresentava fortes características mítico-religiosas. De acordo com Crivellato e Ribatti (2007), muitos dos conceitos atuais da neurociência moderna encontram suas origens nas especulações dos antigos médicos e filósofos gregos. Entretanto, o presente trabalho demonstra a existência de culturas ainda mais antigas preocupadas em encontrar soluções para as mesmas questões que estiveram presentes na Grécia Antiga, assim como na ciência atual.

Acredita-se que os primeiros hominídeos, bem como os humanos pré-históricos, já atribuíam grande importância ao cérebro e o relacionavam ao controle das funções mentais. Após o surgimento da escrita, pode-se constatar que as primeiras civilizações humanas preocupavam-se em compreender o funcionamento do próprio ser humano, bem como em produzir um sistema de conhecimento que pudesse explicar a natureza da atividade mental. Além do cérebro, outros órgãos, como o coração e o fígado, receberam destaque especial quanto a possíveis associações com a função mental. Entretanto, o conhecimento anatomofisiológico desses sistemas corporais apresentava certas limitações.

Ao mesmo tempo, o conhecimento da natureza humana desenvolvido por essas civilizações apresentava um intricado amálmaga entre idéias de cunho lógico-abstrato e pensamentos mítico-religiosos. Assim, conceitos sobre corpo, mente (ou alma), doença e saúde entrelaçavam-se com conceitos religiosos e culturais. É interessante notar que esse tipo de conhecimento surgiu aparentemente de forma independente em cada uma dessas sociedades humanas, e representam as primeiras tentativas de responder a tais questões.

Apesar do aparente isolamento entre essas civilizações, é possível que a proximidade geográfica tenha permitido 
certa comunicação entre suas culturas, possibilitado influências entre elas. Elementos de uma determinada cultura podem ter sido trocados com outra. Entretanto, cada uma delas desenvolveu um conjunto de conhecimento e práticas socioculturais relativamente específicas.

O grande avanço das neurociências na atualidade vem permitindo compreender cada vez mais os diferentes circuitos neurais associados às diferentes funções mentais (ver, por exemplo, Landeira-Fernandez \& Silva, 2007). Contudo, questões fundamentais acerca da natureza da mente humana permanecem em aberto (Bennett \& Hacker, 2003; P. M. Churchland, 2004; P. S. Churchland, 1996). No cerne de todas essas discussões (tanto as atuais quanto as antigas) residem as questões mais óbvias, mas ao mesmo tempo, as mais intrigantes: qual a origem da mente humana?; qual a natureza real dos processos e estados mentais?; em que meio eles ocorrem e como se relacionam com o mundo físico? Pelo que foi exposto, pode-se concluir que essas questões, presentes na ciência contemporânea, estiveram também presentes nas primeiras civilizações humanas.

A descrição de alguns ele-mentos do passado histórico-cultural da humanidade certamente contribui para a tentativa de melhor compre-ender determinadas questões atuais. Ao nos debruçarmos mais atentamente sobre o desenvolvimento histórico dos conceitos que tratam da relação entre mente e corpo (e, conseqüentemente, cérebro), nos damos conta de que sempre houve uma tentativa de responder a tais questões. A busca, nessas culturas, de subsídios históricos acerca do debate mente-corpo revela também uma tentativa de traçar uma história da nossa própria existência.

\section{Referências}

Adamson, P. B. (1991). Surgery in ancient Mesopotamia. Medical History, 35, 428-435.

Andrushko, V. A., \& Verano, J. W. (2008). Prehistoric trepanation in the Cuzco region of Peru: A view into an ancient Andean practice. American Journal of Physical Anthropology, 137(1), 4-13.

Bennett, M. R., \& Hacker, P. M. S. (2003). Philosophical foundations of neuroscience. Oxford, UK: Blackwell Press.

Biggs, R. D. (1995). Medicine, surgery, and public health in ancient Mesopotamia. In J. M. Sasson (Ed.), Civilizations of the ancient Near East. New York: Charles Scribner's Sons.

Birchette, K. P. (1973). The history of medical libraries from 2000 b.C. to 1900 a.D. Bulletin Medical Library Association, 61(3), 302-308.

Blos, V. T. (2003). Cranial surgery in ancient Mesoamerica. In Mesoweb. Retrieved November 12, 2008, from http:// www.mesoweb.com/features/tiesler/Cranial.pdf

Boisaudin, E. V. (1988). Cardiology in ancient Egypt. Texas Heart Institutional Journal, 15(2), 80-85.

Broca, P. (1867). La trépanation chez lês Incas. Bulletin de l'Académie Nationale de Médecine, 32, 866-871.

Carvalho, L. A. V. (1996). Teoria da mente: A alma humana em busca de si mesma. In S. Fuks (Ed.), Descartes 400 anos: Um legado científico e filosófico. Rio de Janeiro, RJ: Relume Dumará.
Churchland, P. M. (2004). Matéria e consciência: Uma introdução contemporânea à filosofia da mente. São Paulo, SP: Editora da Universidade Estadual Paulista "Júlio de Mesquita Filho".

Churchland, P. S. (1996). Neurophilosophy: Toward a unified science of the mind-brain. Cambridge, MA: MIT Press.

Clower, W. T., \& Finger, S. (2001). Discovering trepanation: The contribution of Paul Broca. Neurosurgey, 49(6), 14171426.

Crivellato, E., \& Ribatti, D. (2007). Soul, mind, brain: Greek philosophy and the birth of neuroscience. Brain Research Bulletin, 71, 327-336.

Ehling, D. (2001). Oriental medicine: An introduction. Alternative Therapies in Health and Medicine, 7(4), 71-82.

El Gindi, S. (2002). Neurosurgery in Egypt: Past, present, and future-from pyramids to radiosurgery. Neurosurgery, 51(3), 789-795.

Feldman, R. P., \& Goodrich, J. T. (1999). The Edwin Smith surgical papyrus. Child's Nervous System Journal, 15 281-284.

Feldman, R. P., \& Goodrich, J. T. (2001). Psychosurgery: A historical overview. Neurosurgery, 48, 647-659.

Finger, S. (1994). Origins of neuroscience: A history of explorations into brain function. New York: Oxford Press.

Finger, S. (2000). Minds behind the brain: A history of the pioneers and their discoveries. New York: Oxford Press.

Finger, S., \& Clower, W. T. (2001). Victor Horsley on "trephining in Pre-historic Times". Neurosurgery, 48, 911-918.

Finger, S., \& Fernando, H. R. (2001). E. George Squier and the discovery of cranial trepanation: A landmark in the history of surgery and ancient medicine. Journal of the History of Medicine and Allied Sciences, 56, 353-381.

Gerszten, P. C., Gerszten, E., \& Allison, M. J. (1998). Neurosurgery, 42, 1145-1151.

Gross, C. G. (1998). Brain, vision, memory: Tales in the history of neuroscience. Cambridge, MA: Bradford Book.

Gross, C. G. (1999a). A hole in the head. The Neuroscientist, 5, 263-269.

Gross, C. G. (1999b). "Psychosurgery" in renaissance art. Trends in Neurosciences, 22, 429-431.

Hong, F. F. (2004). History of medicine in China: When medicine took an alternative path. McGill Journal of Medicine, 8(1), 74-84.

Horsley, V. (1888). Trephining in the Neolithic period. The Journal of the Anthropological Institute of Great Britain and Ireland, 17, 100-106.

Jackes, M. K. (2004). Osteological evidence for Mesolithic and Neolithic violence: Problems of interpretation. In M. Roksandic (Ed.), Violent interactions in the Mesolithic: Evidence and meaning (pp. 23-39). Oxford, UK: BAR International Series.

Jensen, R. L., \& Stone, J. L. (1997). Benjamin Winslow Dudley and early American trephination for posttraumatic epilepsy. Neurosurgery, 41(1), 263-268.

Kak, S. C. (1997a). On the science of consciousness in ancient India. Indian Journal of History of Science, 32, 105-120.

Kak, S. C. (1997b). Science in India. In S. Sridhar, \& N. Mattoo (Eds.), Ananya: A portrait of India (pp. 399-420). New York: AIA

Kinnier, W. J. V., \& Reynolds, E. H. (1990). Translation and analysis of a cuneiform text forming part of a babylonian treatise on epilepsy. Medical History, 34, 185-198. 
Kristensen, C. H., Almeida, R. M. M., \& Gomes, W. B. (2001) Desenvolvimento histórico e fundamentos metodológicos da neuropsicologia cognitiva. Psicologia: Reflexão e Crítica, 14, 259-274.

Krivoy, A., Krivoy, J., \& Krivoy, M. (2002). Aspectos neuroquirúrgicos parciales del papiro de Edwin Smith. Gaceta Médica de Caracas, 110, 386-391.

Lad, V. (2001) Textbook of Ayurveda: Fundamental principles: Vol. 1. Albuquerque, NM: The Ayurvedic Press.

Landeira-Fernandez, J., \& Silva, T. A. (Eds.). (2007). Intersecções entre psicologia e neurociências. Rio de Janeiro, RJ: MedBook.

Lillie, M. C. (1998). Cranial surgery dates back to Mesolithic. Nature, 391, 854.

Liu, C. Y., \& Apuzzo, M. L. J. (2003). The genesis of neurosurgery and the evolution of the neurosurgical operative environment: Part I - Prehistory to 2003. Neurosurgery, 52(1), 3-19.

Lyssenko, V. (2004). The human body composition in statics and dynamics: Ayurveda and the philosophical schools of Vaisesika and Samkhya. Journal of Indian Philosophy, 32, 31-56.

Mariani-Costantini, R., Catalano, P., di Gennaro, F., di Tota, G., \& Angeletti, L. (2000). New light on cranial surgery in ancient Rome. The Lancet, 355, 305-307.

Marino-Junior, R., \& Gonzales-Portillo, M. (2000). Preconquest peruvian neurosurgeons: A study of Inca and Pre-Columbian trephination and the art of medicine in ancient Peru. Neurosurgery, 47, 940-950.

Martín-Araguz, A., Bustamante-Martínez, C., Emam-Mansour, M. T., \& Moreno-Martínez, J. M. (2002). Neurociencia em el Egipto faraónico y em la escuela de Alejandría. Revista de Neurología, 34, 1183-1194.

Méndez, F. G. R., Botella, M., \& Vargas II, L. (2001). Medicina y teorías de la enfermedad en el Viejo Mundo: la antigüedad remota. Revista del Instituto Nacional de Enfermedades Respiratorias, 14(1), 178-195.

Menon, I. A., \& Haberman, H. F. (1969). Dermatological writings of ancient India. Medical History, 13, 387-392.

Moodie, R. L. (1917). The sources of anatomical literature. The American Naturalist, 51(604), 193-208.

Moore, J. A. (1988). Understanding nature: Form and function. American Zooloogist, 28, 449-584.

Munro, R. (1891). On trepanning the human skull in prehistoric times. Proceedings of the Society, 26, 5-33.

Oppenheim, A. L. (1964). Ancient Mesopotamia: Portrait of a dead civilization. Chicago: University Press.

Persuad, T. V. N. (1984). Early history of human anatomy. Springfiled, IL: Charles C. Thomas.

Piek, J., Lidke, G., Terberger, T., von Smekal, U., \& Gaab, M. R. (1999). Stone Age skull surgery in MecklenburgVorpommern: A systematic study. Neurosurgery, 45, 147-151.

Prioreschi, P. (1995). A history of medicine. Omaha, NE: Horatius Press.

Puigbó, J. J. (2002). El papiro de Edwin Smith y la civilización egípcia. Gaceta Médica de Caracas, 110, 378-385.

Nasser, M. (1987). Psychiatry in Ancient Egypt. Bulletin of the Royal College of Psychiatrists, 11, 420-422.

Rao, M. S. (1968). The history of medicine in India and Burma. Medical History, 12(1), 52-61.

Rajgopal, L., Hoskeri, G. N., Bhuiyan, P. S., \& Shyamkishore, K. (2002). History of anatomy in India. Journal of Postgraduate Medicine, 48(3), 242-245.
Reuben, A. (2004). The body has a liver. Hepatology, 39(4), 1179-1181.

Ribas, G. C. (2006). Das trepanações pré-históricas à neuronavegação: Evolução histórica das contribuições da neuroanatomia e das técnicas de neuroimagem à prática neurocirúrgica. Arquivos Brasileiros de Neurocirurgia, 25(4), 166-175

Saggs, H. W. F. (1965). Everyday life in Babylonia and Assyria. London: Batsford.

Spiegel, A. D., \& Springer, C. R. (1997). Babylonian medicine, managed care and codex Hammurabi, circa 1700 b.C. Journal of Community Health, 22(1), 69-89.

Scurlock, J. A. (1995). Death and the afterlife in the ancient Mesopotamia thought. In J. M. Sasson (Ed.), Civilizations of the ancient Near East. New York: Charles Scribner's Sons.

Stol, M. (1992). Diagnosis and therapy in Babylonian medicine. Science in Ancient Mesopotamia, 3, 14-15.

Subbarayappa, B. V. (2001). The roots of Ancient medicine: An historical outline. Journal of Biosciences, 26(2), 136144.

Trinkaus, E., \& Zimmerman M. R. (2005). Trauma among the Shanidar Neandertals. American Journal Physical Anthropology, 57(1), 61-76.

Wagner, C. (1890). A case of trephining for general paresis. American Journal of Insanity, 47, 59-65.

Walker, P. L. (2001). A bioarchaeological perspective on the history of violence. Annual Review of Anthropology, 30, 573596.

Willerson, J. T., \& Teaff, R. (1996). Egyptian contributions to cardiovascular medicine. Texas Heart Institute Journal, 23(3), 191-200.

Wilkins, R. H. (1964). Neurosurgical classic - XVII. Edwin Smith surgical papyrus. Journal of Neurosurgery, 21(2), 240244.

Wu, L., Davis, T. L., \& Po-Wang, W. (1932). An ancient Chinese treatise on alchemy entitled Ts'na T'ung Ch'i. Isis, 18, 210-289. 